American Journal of Environmental Sciences 5 (3): 267-272, 2009

ISSN 1553-345X

(C) 2009 Science Publications

\title{
A Gate to Gate Assessment of Environmental Performance for Production of Crude Palm Kernel Oil Using Life Cycle Assessment Approach
}

\author{
S. Vijaya, A.N. Ma and Y.M. Choo \\ Engineering and Processing Division, Malaysian Palm Oil Board, \\ No. 6 Persiaran Institute Bandar Baru Bangi, 43000 Kajang Selangor Malaysia
}

\begin{abstract}
Problem statement: The oil palm industry is an export orientated industry which heavily relies on the world market. In 2007 alone the total export earnings reached RM 45.1 billion. It is essential that the oil palm industry is ready to meet the higher expectation of its overseas customers on the environmental performance of the industry. Life Cycle Assessment (LCA) is a tool to evaluate the environmental impacts of a product or process throughout its entire life cycle. To identify the potential environmental impacts associated with the production of CPKO and to use this assessment for evaluating opportunities to overcome the potential impacts. Approach: This study had a gate to gate system boundary that starts with the collection and transportation of the palm kernel from the palm oil mills to the production of Crude Palm Kernel Oil (CPKO) at the kernel crushing plants. Six kernel crushing plants were selected to collect inventory data which consists of inputs of raw materials and energy; outputs of solid, liquid and gaseous wastes. Five crushing plants used electricity directly from the grid while one crushing plant used the electricity generated at the neighboring palm oil mill for processing. This study compared the Life Cycle Impact Assessment (LCIA) of two scenarios namely; when the crushing plants uses electricity from the grid versus the crushing plant which uses electricity generated from the palm oil mill. The LCIA was conducted using the Simapro software and the EcoIndicator 99 methodology. Results: For scenario one there was two potential impacts mainly from the electricity consumption from the grid for processing and diesel consumption for transporting the palm kernel from the mills. For scenario two, the potential impact from the electricity consumption from the grid was reduced due to the use of renewable energy from the palm oil mill and the impact from diesel consumption was reduced due to the short distance for transporting the palm kernel. Conclusion: It was recommended that more kernel crushing plants should be integrated with the palm oil mills to over come these impacts.
\end{abstract}

Key words: Crude palm kernel oil, kernel crushing plants, life cycle assessment, palm oil industry

\section{INTRODUCTION}

The world is demanding for economic growth but yet this growth must be achieved through environmental conservation while enhancing the quality of human life. Sustainability is about preserving the health of the biosphere and the efficient use of natural resources like air, water, land, flora and fauna ${ }^{[2]}$. Sustainable development has been popularly defined as development that meets the needs of the present without compromising the ability of future generations to meet their own needs ${ }^{[7]}$. This clarion call has resulted in the recognition of environmental issues to increase enormously from the last decade onwards gaining momentum each year. The consumers or public have become more aware that the consumption of manufactured products and services offered contributes to adverse effects on resources and the quality of the environment and that these effects can occur at all stages of the life cycle and not just during manufacturing.

Since the late 1990s there is also a widespread emergence of eco-labeling criteria and EMS which extends into agriculture products and processing sectors. Eco-labeling is slowly evolving to become a market-based voluntary mechanism in the greening of agriculture products supply chain. Eco-label Type III specifically requires a LCA for certification.

Life Cycle Assessment (LCA) is a tool to evaluate the environmental impacts of a product or process throughout its entire life cycle ${ }^{[5]}$. LCA was first developed as a method to evaluate the impacts of a product over its entire life cycle, but it has since grown

Corresponding Author: S. Vijaya, Engineering and Processing Division, Malaysian Palm Oil Board, No.6 Persiaran Institute, Bandar Baru Bangi, 43000 Kajang Selangor Malaysia Tel: 603-87694470 Fax: 603-89263827 
to be used in evaluating the environmental impacts of a business activities or a nation's economic activity as well. Over the last ten years there has been a rapid expansion in the demand for LCA studies to chart the environmental performance of products. Industries, environmental experts, academics, regulatory authorities, politicians, consumers associations, environmental organizations and the general public want to know how to assess the environmental quality of products and production process. LCAs have become a common environmental management tool and a good analytical method for assessing and optimizing the environmental quality of a system over the whole life cycle ${ }^{[6]}$.

The oil palm industry is a very important industry which contributes immensely towards the economy of the country. In 2007 alone the total exports of oil palm products, constituting of palm oil, palm kernel oil, palm kernel cake, oleo chemicals and finished products was 19.56 million tones resulting to a total export earnings of RM 45.1 billion $^{[1]}$. Exports of palm kernel oil increased by $14.1 \%-1.06$ million tonnes in 2007. USA was the major market for palm kernel oil in 2007 with 0.24 million tonnes, followed by China PR, the EU and Japan. However exports of palm kernel cake declined by 1.9\%-2.09 million tonnes from 2.13 million tonnes in 2006. The major palm kernel cake export markets were the European Union, South Korea and Australia ${ }^{[1]}$.

The oil palm industry is an export orientated industry which heavily relies on the world market. Therefore it is vital for the oil palm industry to be sustainable and competitive to increase its long-term profitability and sustainability. It is essential that the oil palm industry is ready to meet the higher expectation of its overseas customers on the environmental performance of the industry.

The oil palm Fresh Fruit Bunch (FFB) is a unique crop. Two types of oil can be obtained from this crop. A palm fruit is drupe oval in shape and contains a kernel which is the seed (nut). The kernel is surrounded by the fruit wall made up of hard shell (endocarp), fibrous fruit pulp or oil bearing tissue (mesocarp) and the skin as shown in Fig. $1^{[3]}$. Within the nut there is the kernel. As shown in the cross section in Fig. 1 of the oil palm fruit lets, the crude palm oil is obtained from the mesocarp while palm kernel oil is obtained from the kernel within the nut.

Crude palm oil is processed at the palm oil mills and the kernel which is cracked from the nut is a by product at the palm oil mills. This kernel is then shipped by trucks to nearby kernel crushing plants that process these kernels into Crude Palm Kernel Oil (CPKO). This is carried out by a continuous screw, commonly known as an expeller.

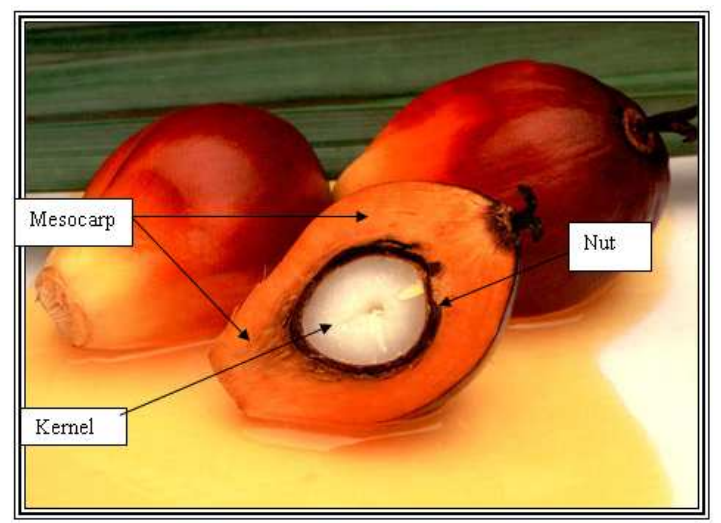

Fig. 1: Cross section of oil palm fruit let

The expeller consists basically of a perforated cylindrical cage in which runs a worm or screw. The discharge end of the cage is fitted with an adjustable cone which restricts the discharge opening of the cage. The rotation of the worm transports the meal towards the outlet end of the perforated cage and the outlet is restricted by the cone, a pressure is built up in the cage thus causing the oil to be squeezed out of the meal. The internal pressure in the cage is regulated by adjustments to the outlet cone. The extracted oil flows through the perforations in the cage whilst the solid matter, or cake, is discharged from the opening around the cone. When efficiently operated the residual oil in the cake is between $5-6 \%{ }^{[4]}$.

Objective: The objectives of this study are to:

- Identify the potential environmental impacts associated with the production of CPKO

- To use this assessment for evaluating opportunities to overcome the potential impacts

\section{MATERIALS AND METHODS}

Six kernel crushing plants were chosen for this study. Five of the chosen crushing plants use electricity directly from the national grid supply for processing while one crushing plant uses the electricity generated at the neighboring palm oil mill. The inventory data which consisted of raw material, energy consumption, wastes and emissions were collected over a period of one year from each kernel crushing plant. A Life cycle Inventory (LCI) for every tonne of $\mathrm{CPKO}$ produced was created and these data were then input into the SimaPro Software Version 7.1 to carry out the Life Cycle Impact Assessment (LCIA). The Eco-Indicator 99 methodology was selected to conduct the LCIA. 
System boundary and functional unit: This study has a gate to gate system boundary which starts at the palm oil mills when the palm kernel is collected up till the production of $\mathrm{CPKO}$ at the kernel crushing plants. Figure 2 shows the various stages included in the system boundary. The functional unit for this study is one tonne of CPKO produced at the kernel crushing plant.

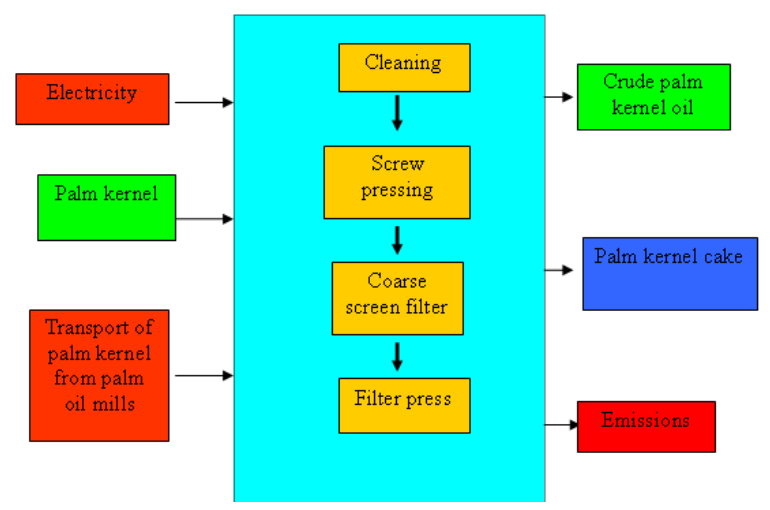

Fig. 2: System boundary of mechanical extraction of crude palm kernel oil
Limitations/constraints: The simapro software used is an European software with European data. However, the software is generic and Malaysian data has been input into the database wherever possible to conduct this study. However the background data has been adopted from the database it self for example the diesel used due to lack of Malaysian data. This is one of the main constrains in determining the LCIA as Malaysia lacks the much needed background data. With this constrain in mind the LCIA is conducted.

\section{RESULTS}

Using the inventory data collected over a period of one year from each kernel crushing plant, the Life Cycle Inventory (LCI) was created for every one tonne of CPKO produced at the kernel crushing plant as shown in Table 1.

LCIA was conducted for the five kernel crushing plants A to E which uses electricity from the grid and are all located at a distance from the palm oil mills as shown in Fig. 3 and 4. Figure 5 shows the LCIA for kernel crushing plant $F$ which uses renewable energy and located within three $\mathrm{km}$ of the palm oil mill.

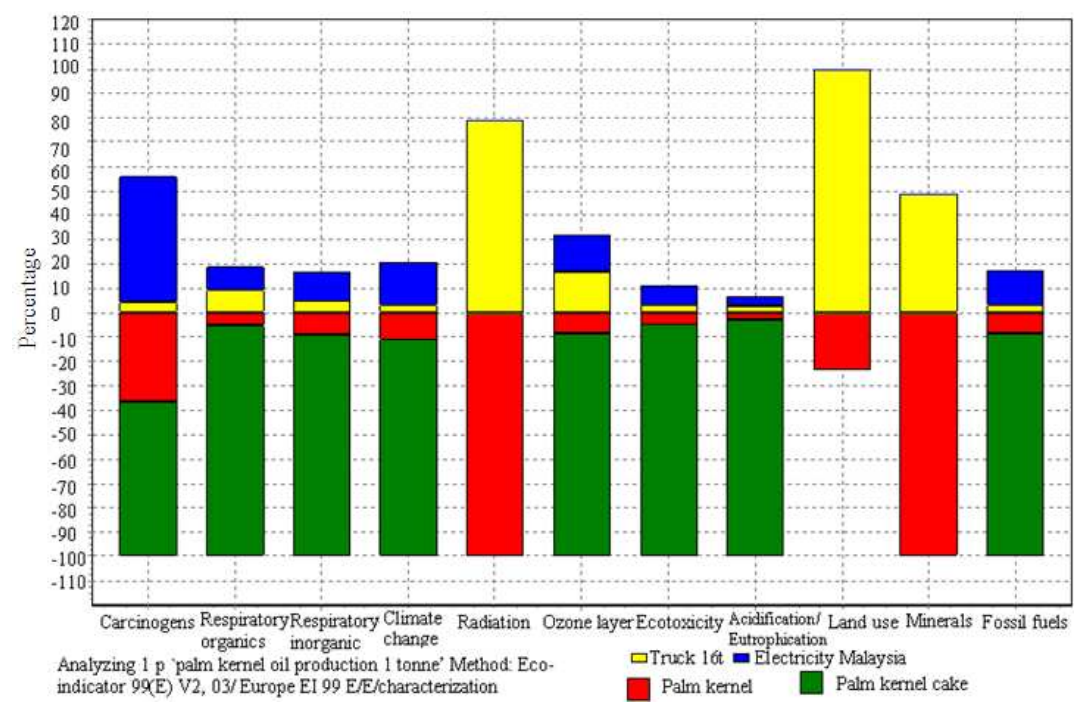

Fig. 3: Characterization of the LCIA for 1 tonne of CPKO produced

Table I: Life Cycle Inventory for the production of one tonne of CPKO

\begin{tabular}{lrrrrrrrr}
\hline Crushing Plant & A & B & C & D & E & Average & Std Dev. & F \\
Envt. Inputs: & & & & & & & & \\
Palm Kernel (t) & 2.3500 & 2.300 & 2.2000 & 2.2700 & 2.2000 & 2.2700 & 0.060 & 2.3800 \\
Electricity form Grid (kWh) & 275.0200 & 238.190 & 283.4700 & 234.6200 & 294.3600 & 265.1300 & 27.140 & 26.0200 \\
Electricity generated at POM (kWh) & - & - & - & - & - & - & - & 249.0000 \\
Distance (km) & 62.5000 & 80.000 & 77.5000 & 90.0000 & 85.0000 & 79.0000 & 10.400 & 3.0000 \\
Diesel consumption (L) & 11.2500 & 14.400 & 13.9500 & 16.2000 & 15.3000 & 14.2200 & 1.870 & 0.9000 \\
Envt. Outputs: & & & & & & & & \\
Palm kernel cake (t) & 1.1300 & 1.190 & 1.0000 & 1.1800 & 1.1000 & 1.1200 & 0.100 & 1.2200 \\
\hline
\end{tabular}




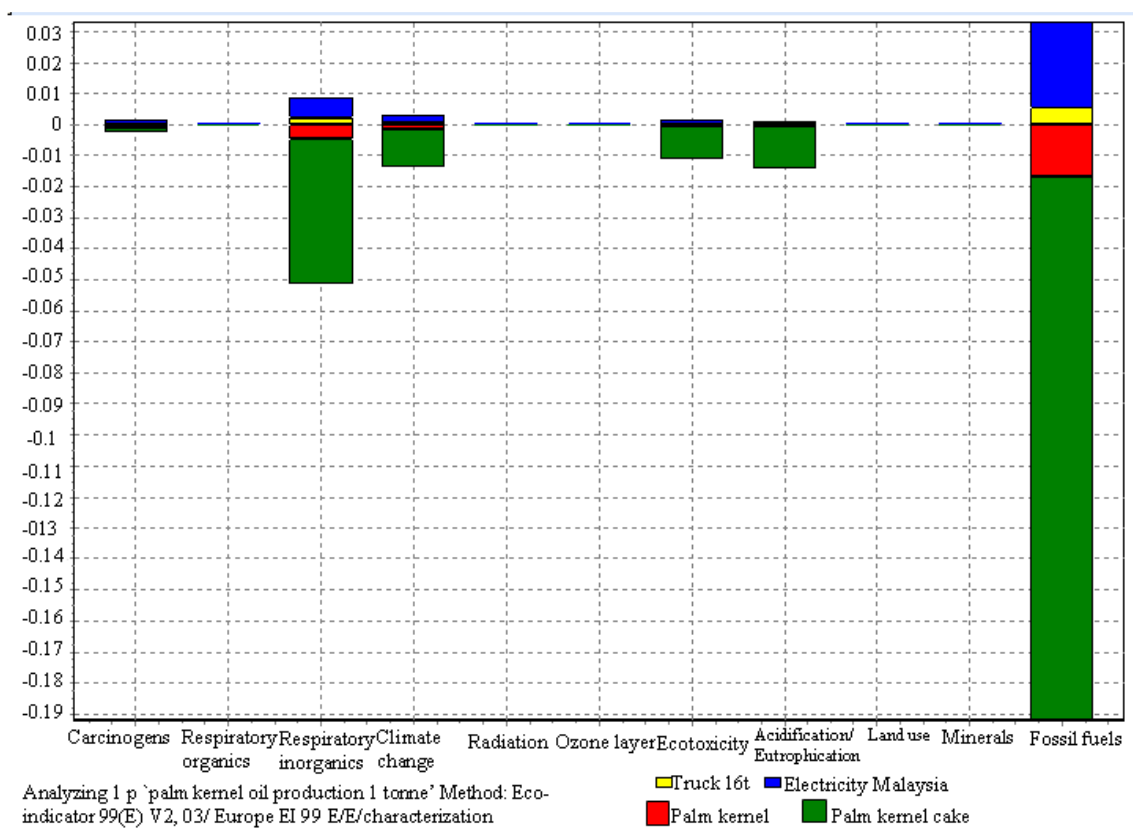

Fig. 4: Normalization of the LCIA for 1 tonne CPKO produced

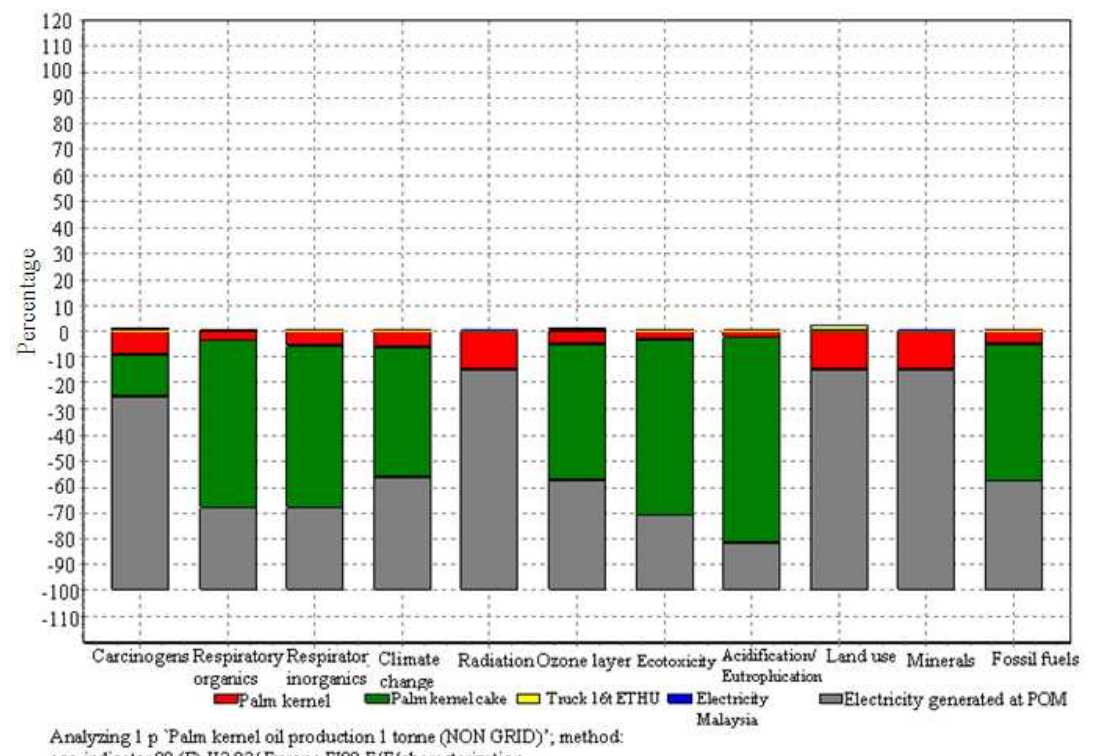
eco-indicator 99 (E) V2,03/ Europe E199 E/E/characterization

Fig. 5: Characterization of the LCIA for 1 tonne of CPKO produced (Non-grid energy supply)

\section{DISCUSSION}

Almost all the kernel crushing plants in Malaysia uses the mechanical method which is basically the direct crushing and pressing of the kernels to squeeze out the kernel oil from the kernels. The waste from this process is the palm kernel cake which is the crushed kernel after the oil is pressed out. The selected crushing plants all have identical processing methods and conditions. These crushing plants are typical of the majority of the crushing plants in Malaysia. All these kernel crushing plants use the double squeezing method to press out as much CPKO as possible.

Based on Table 1 one of the major environmental inputs is the energy consumption for the whole processing of palm kernel into CPKO. This energy 
source is the electricity supply from the national grid which is the biggest input within this system boundary. In average about $265.13 \mathrm{kWh}$ electricity is consumed for every one tonne of CPKO produced.

Kernel crushing plants $\mathrm{F}$ is also identical in the processing methods with the other crushing plants but it has one big difference which is the source of the energy. Kernel crushing plant A to $E$ all use only one energy source for the processing which is the electricity from the national grid supply. However kernel crushing plant $F$ uses the electricity supply from the neighboring palm oil mill. Palm oil mills generate electricity by burning the biomass in the furnace to run a turbine which generates electricity for its own milling process as well as for the kernel crushing plant nearby. In the palm oil mills mesocarp fiber and shell are used as fuel in the boiler and are burnt to produce heat to convert water into steam. This steam is then used to run a turbine which generates electricity for the milling process and the whole mill compound. The mesocarp fiber and shell are actually wastes from the FFB which are then recycled as boiler fuel. The mesocarp fiber is the waste after oil has been pressed out of the mesocarp of the fruit. The shell is the outer layer of the nut which when cracked produces kernel and shell. However kernel crushing plant F still consumes some electricity from the national grid supply when the palm oil mill is not processing. However it should be noted that the amount is only $26.02 \mathrm{kWh}$ per tonne of CPKO.

The other environmental input is the diesel consumption. This diesel consumption is from the trucks or Lorries that transport the palm kernel from the palm oil mills to the kernel crushing plants. The distance varies from mill to mill but in average it can be said that the kernel travels for a distance of $79 \mathrm{~km}$. However for kernel crushing plant $\mathrm{F}$ which is situated right beside the palm oil mill, the distance is cut down to only about $3 \mathrm{~km}$. This explains the figures $0.9 \mathrm{~L}$ of diesel per ton $\mathrm{CPKO}$ for this crushing plant compared to $14.22 \mathrm{~L} \mathrm{ton}^{-1} \mathrm{CPKO}$ for the other five kernel crushing plants.

The other environmental input is of course the palm kernel itself which ranges from about 2.202.35 tonnes tonne ${ }^{-1}$ CPKO. This range is based on the kernel extraction rate of each crushing plant which directly reflects on the pressing efficiency.

The main environmental outputs are the emissions from the trucks and the palm kernel cake. Due the use of mechanical pressing, there is some oil retained in the palm kernel cake resulting it to be a good source of animal feed. All the palm kernel cakes are either exported or used internally as animal feed.
Based on Fig. 3, the LCIA shows that there are two major parameters causing the potential impacts in all the impact categories. The parameters causing the potential impacts are from the transportation of the palm kernel from the palm oil mills to the kernel crushing plants and the electricity consumption from the grid for processing. The potential impact from the transportation is mainly from the diesel consumption from the trucks or Lorries. Due to the distance between the palm oil mills and the kernel crushing plants, transporting the kernel which uses fossil fuel is causing the potential impact under all the impact categories. The kernel crushing plants in Malaysia are situated nearer to the ports for easier access for exporting their CPKO. This is the reason for the distance between the palm oil mills and the kernel crushing plants. The palm oil mills are normally located nearer to the oil palm plantations. The other parameter causing the potential impacts is the electricity consumption from the national grid. Again being a fossil fuel based energy source, this also contributes as a potential impact under all the impact categories.

Palm kernel cake is the waste after which the palm kernel oil has been squeezed out. This palm kernel cake becomes a savings as it is used as animal feed. Since both electricity and transportation seem to be causing the potential impact in all impact categories, normalization is carried out to examine which impact is more significant or harmful. The Normalization results are as shown in Fig. 4.

When normalized, the potential impact from electricity seems to be more prominent than transportation. This can be explained due to the fossil based fuel used to produce this energy which uses coal, oil and natural gas compared to the transportation which only uses diesel. Another reason is also because the quantity of the diesel consumption is much less that the electricity consumption. From the results above it is very clear that the main parameter causing the impact is from the electricity consumption from the grid followed by the transportation of the palm kernel which uses diesel.

Most kernel crushing plants in Malaysia predominantly uses electricity from the national grid for their processing. However there are some kernel crushing plants that use alternate energy sources. Although this is quite rare but there are crushing plants that are located right beside the palm oil mill. Kernel crushing plant $\mathrm{F}$ is such a plant that is located within the boundaries of the palm oil mill. This kernel crushing plant uses the electricity generated at the palm oil mill for their processing. When there is a shortage or shut down of the palm oil mill, only then they use the grid supply as a back up. 
In order to compare the differences between kernel crushing plants which use electricity from the grid and are located far away with a kernel crushing plant which uses electricity from the neighboring palm oil mill and is located nearby, the LCIA for kernel crushing plant F was conducted and the results are shown in Fig. 5.

Based on the results it clearly shows that when the kernel crushing plant is located either within the palm oil mill compound or nearby the impact from the diesel consumption is very little. Same goes for the potential impact from the electricity consumption from the grid. Because this kernel crushing plant uses the electricity which is generated at the palm oil mill, the fossil based energy is displaced.

\section{CONCLUSION}

The present reality is that we have to deal with environmental deterioration. Mitigation using the LCA concept must be viewed as an investment for our future generation if not for ourselves because efforts in mitigation of environmental degradation will translate into a concerted effort to combat the many environmental impacts resulting from mismanagement of natural resources and energy. LCA is the tool that puts the development of products, materials and their associated processing steps in the context of the most important issue of the moment i.e., sustainability.

On the whole within the system boundary the production of CPKO has only two major environmental impacts and both are due to the use of fossil fuels. Scenario two with a kernel crushing plant integrated in the palm oil mill shows that are the best way to overcome the potential impacts. In view of this, more kernel crushing plants should be integrated with the palm oil mills to over come these impacts.

\section{ACKNOWLEDGEMENT}

The researchers would like to thank the oil palm industry for allowing us to conduct the study at their kernel crushing plants.

\section{REFERENCES}

1. Basri, W., 2008. Overview of Malaysian oil palm industry 2007. Malaysian Palm Oil Board. Selangor, Malaysia. http://econ.mpob.gov.my/economy/overview07.htm

2. Chan, K.W., 2004. The role of environmental management systems standards for enhanced market share and increased competitiveness. Proceeding of the 4th National Seminar on ISO 14000 Series of Environmental Management System Standards, Oct. 11, Malaysian Palm Oil Board, Selangor.

3. Hamdan, M., M. Maznah, T.Y. Chew, A. Fadzil, S.S.M. Syed Anuar and N.W.A.H. Wan Siti, 2000. Feasibility study on Grid Connected Power Generation Using Biomass Cogeneration Technology. A study Funded by Malaysian Electricity Supply Industry Trust Fund. Pusat Tenaga Malaysia Publications, pp: 5-6

4. Ngan, M.A., 1994. Extraction of Crude Palm Oil and Palm Kernel Oil. Selected Readings on Palm Oil and Its uses. Palm Oil Research Institute of Malaysia Publisher, pp: 33.

5. SETAC, 1993. Guidelines for Life-Cycle Assessment: A Code of Practice. SETAC Publications, Brussels, pp: 2.

6. Stalmans, M., H. Berenbold, J. Berna, L. Cavali, A. Dillarstone, M. Franke, F. Hirsinger, D. Janzen, K. Kosswig, D. Postlethwaite, Th. Rappert, C. Renta, D. Scharer, K.P. Schick, W. Schul, H. Thomas and R. Van Sloten, 1995. European life- cycle inventory for detergent surfactants production. Munchen. Tenside Surfactant Detergent, 32: 84-85. http://cat.inist.fr/?aModele $=$ afficheN\&cpsidt $=3533$ 603

7. UNCED-United Nations Conference on Environment and Development, 2002. Sustainable Development. Johannesburg Summit, Aug. 26Sept.4, Johannesburg. 